\title{
Explore the Factors of School Bullying from the Ecosystem Theory
}

\author{
Helin Qiu \\ Campus of Psychology, Inner Mongolia Normal University, Huhhot, China \\ Email: qhllove29@163.com
}

How to cite this paper: Qiu, H.L. (2021) Explore the Factors of School Bullying from the Ecosystem Theory. Open Access Library Journal, 8: e8165.

https://doi.org/10.4236/oalib.1108165

Received: November 8, 2021

Accepted: December 11, 2021

Published: December 14, 2021

Copyright (C) 2021 by author(s) and Open Access Library Inc.

This work is licensed under the Creative Commons Attribution International License (CC BY 4.0).

http://creativecommons.org/licenses/by/4.0/

\section{(c) (i) Open Access}

\begin{abstract}
School bullying is a repetitive act of aggression designed to intentionally harm another person physically or mentally, including physical aggression, verbal aggression, relational aggression and cyber aggression. The factors that influence bullying on campus can be analyzed from many angles. In this paper, the ecosystem theory is selected to analyze the environmental factors that cause school bullying. These include microsystems of the direct environment of individual activities and interactions, intermediate systems of linkages or interrelations between microsystems. Exosystems that are not directly involved but have an impact on their development. Macrosystems that exist in the three systems of culture, subculture and social environment, and the time and latitude of psychological changes in individual growth. Hope to find the cause of campus bullying, and use this as a reference to campus bullying intervention.
\end{abstract}

\section{Subject Areas}

Educational Psychology

\section{Keywords}

School Bullying, Ecosystem Theory, Factors

\section{Introduction}

In recent years, school bullying has not only become a hot topic, but also aroused great attention from all walks of life on school safety and students' mental health.

Bullying in schools is on the rise. There is an urgent need to investigate the causes and intervene to prevent bullying from happening again. The occurrence of bullying is not a problem for students themselves. We need to do a compre- 
hensive analysis from different angles. Based on the relationship between environmental factors and campus bullying mentioned in ecosystem theory, this paper analyzes the influencing factors of campus bullying from the perspective of ecosystem theory. And as far as possible comprehensive analysis of school bullying causes, looking for a more reasonable and effective way to avoid school bullying.

\section{The Definition of School Bullying}

The Swedish translator of Lorenz's book mentioned the word term mobbning ${ }^{1}$ to refer to the collective attack of one animal against another. In the translation of the book, the mobbning is also referred to characterize the action of a school class or group of soldiers who ganged up on a deviant individual [1]. Despite this linguistic emphasis on the group, Olweus quickly sought to shift the meaning of mobbning to the role of individuals. He argued that a focus on the group obscures the role of individuals, puts the blame on the victim, who may be assumed to provoke the "normal" majority, and treats the group as a temporary constellation [2]. Olweus's work has shaped the prevailing view that bullying is systematic, repetitive harassment of an individual(s) by one or more individuals.

Olweus defined that bullying is an act of repeated aggressive behavior in order to intentionally hurt another person, physically or mentally. Bullying is characterized by an individual behaving in a certain way to gain power over another person.

American psychologist Colette Daiute observes that a society lives in its youth. The problems that youths face are not peripheral to society, but mirror central problems of social life in important ways. This approach may seem obvious in cases of extreme conflict, such as when societies are in the midst of civil war or seeking to rebuild themselves after conflict, or when they are torn apart by intense social, racial or ethnic violence. But it may be the case more generally as well. Understanding the problems youths face is central to understanding the societies in which they live.

So the book called school bullying suggested that Bullying is an intensification of the processes of marginalisation that occur in the context of dynamics of inclusion/exclusion, which shape groups. Bullying happens when physical, social or symbolic exclusion becomes extreme, regardless of whether such exclusion is experienced and/or intended. One of the central mechanisms of bullying is social exclusion anxiety, which may be alleviated by the production of contempt. This contempt for someone or something may be expressed by behaviour that, for example, humiliates, trivialises or makes a person feel invisible, involves harm to person or property, abuses social-media profiles or disseminates humiliating messages via technological communication. Although some members of the social group may experience these marginalising processes as positive, robbing an "The word "mobbing" (in Swedish, "mobbning") was used in these early Swedish debates and was borrowed by other languages. But "bullying" has now become the standard term in English; thus, we use that word in this paper. 
individual(s) of the social recognition that is necessary for dignity can be a form of psychic torture for those who are targeted [3].

Researchers have also identified several major characteristics of bullying behavior, which encompass different subcategories. Acts of bullying include: physical aggression (e.g., hitting or kicking), verbal aggression (e.g., name calling), indirect/relational aggression (e.g., exclusions from a social group), and more recently cyber aggression.

\section{Ecosystem Theory with School Bullying}

Ecosystem theory, also known as social ecosystem theory, is an individual development model formally proposed by American psychologist Yuri Brownfingbrenner in the 1980s to examine the interaction of human behavior with the outside world to solve real-life problems. Looking at the environment as an interconnected multi-structure system from the inside out and looking at it as a whole provides a theoretical basis for us to understand the complex relationship between human and external social environment [4]. There are four factors that affect individual development, and these factors are collectively referred to as systems, including microsystems, intermediate systems, outer systems, and macro systems.

Focusing on the basic factor characteristics and structure, the analysis and comparison of brown Finn Brenner's ecosystem theory and bullying in primary and secondary schools can be found that there is some commonality between the two. Ecosystem theory combines important theories in ecology, sociology, and psychology, while bullying falls within the sociological category, and bullying is mainly related to psychological theories, such as Bandura's theory of social learning and Erickson's theory of personality development [5]. Therefore, both can use the discipline theory of psychology as the cornerstone. Secondly, the content system of the two is more consistent, the theory of ecosystem expands the concept of "environment", which includes not only the environment around children, but also the larger social environment and cultural environment that affect children's development. The family, social, and cultural environment as a whole (system) studies the interaction between internal members. Research on bullying in schools has found that most of the factors that lead to bullying are influenced by external circumstances, such as community culture. Therefore, the external environment also has an important impact on bullying in schools. Finally, the value of the two goals has a strong correlation, the value of ecosystem theory is based on the analysis of the "four systems view" to promote human development, and the campus bullying factor research adhering to the quality education "people-oriented" value orientation, in promoting individual development, the two have similar value goals.

\section{The Factors Which Affect School Bullying}

There are many factors that affect school bullying, and socio-demographic cha- 
racteristics are often regarded as predictors of school bullying behavior. Some researchers have found that junior high school students have a higher probability of bullying behavior than primary and high school students [6] [7]. Many studies have reported that boys are generally more susceptible to bullying than girls, but recent studies have suggested that gender differences in school bullying are not significant [8], girls are generally more at risk of sexual assault [9]. A survey in the United States found that homosexual students are more vulnerable to bullying than other students [10]. Student health can also enhance or reduce their bullying experience at school [11]. Overweight and obese students are more likely to be victims or perpetrators of bullying than normal weight students. Students with social and psychological problems such as depression and anxiety are very likely to be hurt by their peers at school [12], but psychological problems cannot be used as important predictors of bullying [13]. Students with learning and developmental difficulties have difficulty understanding verbal or non-verbal communication, and weak social skills may hinder their ability to negotiate effectively with peers and are more likely to be bullied on campus [14]. Limited research results indicate that students with high academic performance also suffer from peer-to-peer relationship attacks [15]. However, the main reason for researchers is their appearance and intelligence [16]. Poverty is also a risk factor for school bullying in some areas. Students from poor families are more vulnerable to peer violence at school [17] and agree with the culture of bullying [18]. They even cannot get comfort from their parents [19].

\section{Analysis of School Bullying from the Perspective of Ecosystem Theory}

\subsection{Microsystem}

The most direct influences in bullying behavior among youth are within microsystem, which is composed of individuals or groups of individuals within immediate settings (e.g., home, school) with whom youth have interactions. The microsystem level analysis suggests that assessment of risk factors for bullying behavior needs to consider parent-youth relationships, inter-parental violence, peer relationships, school connectedness, and school environment [20].

\subsubsection{Parent-Child Relationships}

Parent-child research has found that parents' non-participation in their children's growth and life or always with negative interactions in the family are related to bullying [21].

A study by Duncan shows that mothers protect boys who are overprotected, they have no negative experience, they do not have the skills to handle and resolve conflicts, or even develop the autonomy necessary to acquire and maintain their position in a peer group, and therefore always peer bully Object. On the other hand, if the mother is emotionally insulting, hostile and alienates a girl, they will not be able to learn appropriate social skills because the mother has not 
established healthy interpersonal relationships, and they will also become victims due to poor emotional regulation and communication problems [22]. Attachment theory assumes that the quality of caregivers' attachments will affect their interpersonal relationships in the years to come [23], and it can explain why the lack of parental and youth relationships and interactions can affect bullying behaviors. Young children who have a strong attachment to their parents can build more positive relationships with others [24]. Those who do not have a strong attachment to the caregiver may develop poor social skills, which may lead to peer conflict and peer rejection. Lack of secure attachments can also lead to behavioral problems in childhood, such as aggression in school.

\subsubsection{Domestic Violence}

Some scholars have found that witnessing violence between parents is a risk factor for peer conflict [25]. These studies have found that young people who experience parental violence at home are more likely to bully others or fall victim to bullying at school. A study investigated the association between inter-parental violence and bullying in a sample of Italian youth, found that both boys and girls who witnessed violence between their parents were significantly more likely to bully their peers compared to those who were not exposed to interparental violence [26]. Özge PINARCIK [27] surveyed 50 children between the ages of 24 and 36 , he found that children living in fragmented families, children who were victims of domestic violence or child discrimination, and working parents were more likely to be bullied than other children. A study by Feng Jing and Luo Guofen [28] shows that children who have witnessed domestic violence for a long time are more insecure and may even be harmed as they grow up.

\subsubsection{Peer Relationships}

Adolescence is a time when friendship and peer support are essential. Youth seek autonomy and seek social support from friends and peers. Therefore, negative peer relationships and lack of peer support are important risk factors for bullying. Many researchers have found that peers play an important role in bullying victims and committing evil acts. Peer acceptance, popularity and friendship are essential for many adolescents [29]. As Demaray and Malecki [30] point out, peer acceptance is considered a protective factor against peer victimization, and they find that youth with lower peer acceptance and social support are more likely to be bullied.

\subsubsection{School Environment}

A survey of schools with bullying behaviors found that negative factors in the school environment can increase the frequency of bullying and reduce students' sense of security at school [31]. Young people who have a positive knowledge of their school environment are less likely to have external behaviors [32]. These findings demonstrate the importance of the school environment for adolescent psychosocial function [33]. 


\subsection{Mesosystem}

The mesosystem level requires understanding the interrelationship between two or more microsystems, each containing an individual [34]. Teacher participation is a related mid-system risk factor for bullying in schools. Experience in one system (i.e. young teachers) may affect interactions in another system (i.e. young peers). Since students and teachers often interact in school, it is necessary to understand the attitude and level of participation of teachers. Given the contribution of teachers and school officials to the school culture, they can influence the relationship between students and their peers and their perception of the school environment [35].

\subsection{Exosystem}

Exosystem considers all aspects of the environment, rather than including the individual's direct system. Under this system, individual development is influenced by events that occur in the absence of an individual environment [34]. The researchers have consistently found that the likelihood of violence on television [36], video games [37] and the Internet [38] increases the likelihood of aggressive thought and behavior. The theory of social learning provides an explanation for these findings. Young people who show violence in the media may engage in aggressive peer interaction. Studies by Huesmann et al. [36] have shown that identity of offensive characters on television and the realism of TV violence are important risk factors for aggressive behavior. In recent years, Internet (or cyber) bullying has also attracted media and research attention for the use of the Internet to cause harm or discomfort to specific groups of people or to specific groups of people [38]. As more and more young people have access to the Internet, instant messaging, chat rooms and blogs, internet bullying has become a new form of cruel young abuse [38].

\subsection{Macrosystems}

Macrosystem levels are considered "blueprints" for culture, which can determine the social structures and activities that occur at the direct system level [39]. The macrosystem level refers to, for example, cultural beliefs, opportunity structures and hazards, which ultimately affect specific conditions and processes that occur in the microsystem [39]. Behavior is rooted in the culture of the organization and there is a great need to understand the organization, not just the individual. In the context of bullying, it mainly includes two macro-system level factors, including cultural norms and beliefs. Cultural norms and beliefs "culture" is a widespread and complex phenomenon that social scientists conceptualize in many different ways [40]. In developed countries, school norms help perpetuate inequality, alienation, aggression and oppression among students in terms of race, ethnicity, gender and socio-economic background. Walton [41] agrees that bullying is a social and political structure that stems from broader social pressures. Leach [42] examined the role of school and peer group cultural norms in 
the development of gender identity among young people in Zimbabwe, Malawi and Ghana in the context of gender bullying.

\section{Conclusion}

In my opinion, school bullying is closely related to the environment in which an individual lives. Many researchers have used socio-ecological perspectives, including focusing on family, family environment, school climate, community factors, peer status, and influence of peers. Most of these documents emphasize the need for a school-wide and multi-context approach. However, there is still a tendency to focus on specific issues related to individual children, emphasizing the development of empathy and social skills rather than focusing on patterns of interaction between children. There are many factors that affect the causes of school bullying. There are still some contradictory factors and unavoidable environmental factors from the perspective of current ecosystem theory. In addition to continuing to explore this, we should discuss it on a broader scale. Try our best to avoid more school bullying.

\section{Conflicts of Interest}

The author declares no conflicts of interest.

\section{References}

[1] Agevall, O. (2008) The Career of Bullying: Emergence, Transformation, and Utilisation of a New Concept. Rapport No. 29, School of Social Sciences, Växjö University, Sweden, pp. 1-71.

[2] Schott, R.M. (2014) School Bullying: The Social Concept of Bullying: Philosophical Reflections on Definitions.

[3] Schott, R.M. and Sondergaard, D.M. (2014) School Bullying: New Theories in Context. Cambridge University Press. https://doi.org/10.1017/CBO9781139226707

[4] Wang, J. (2016) Poor Academic Dialysis for Middle School Students from the Perspective of Social Ecosystem. High School Political Teaching Reference, No. 36, 52-54.

[5] Luo, N. (2018) Research on Bullying Phenomenon and Countermeasure in Primary and Secondary Schools in China in the Past 5 Years. Master's Thesis, Shaanxi University of Technology, Xi'an.

[6] Dinkes, R., Kemp, J., Baum, K. and Snyder, T.D. (2009) Indicators of School Crime and Safety: 2008. U.S. Department of Education and Justice, Washington DC. https://doi.org/10.1037/e541462009-001

[7] Espelage, D. and Horne, A. (2008) School Violence and Bullying Prevention: From Research Based Explanations to Empirically Based Solutions. In: Brown, R.L.S., Ed., Handbook of Counseling Psychology, 4th Edition, John Wiley and Sons, Hoboken, 588-606.

[8] Goldstein, S.E., Young, A. and Boyd, C. (2008) Relational Aggression at School: Associations with School Safety and Social Climate. Journal of Youth and Adolescence, 37, 641-654. https://doi.org/10.1007/s10964-007-9192-4

[9] Shute, R., Owens, L. and Slee, P. (2008) Everyday Victimization of Adolescent Girls by Boys: Sexual Harassment, Bullying or Aggression? Sex Roles, 58, 477-489. 
https://doi.org/10.1007/s11199-007-9363-5

[10] Kosciw, J.G. (2004) The 2003 National School Climate Survey: The School-Related Experiences of Our Nation's Lesbian, Gay, Bisexual and Transgender Youth. Gay, Lesbian, and Straight Education Network, New York.

[11] Janssen, I., Craig, W.M., Boyce, W.F. and Pickett, W. (2004) Associations between Overweight and Obesity with Bullying Behaviors in School-Aged Children. Pediatrics, 113, 1187-1194. https://doi.org/10.1542/peds.113.5.1187

[12] Klomek, A., Marrocco, F., Kleinman, M., Schonfeld, I.S. and Gould, M.S. (2007) Bullying, Depression, and Suicidality in Adolescents. Journal of the American Academy of Child and Adolescent Psychiatry, 46, 40-49. https://doi.org/10.1097/01.chi.0000242237.84925.18

[13] Bond, L., Carlin, J.B., Thomas, T., Rubin, K. and Patton, G. (2001) Does Bullying Cause Emotional Problems? A Prospective Study of Young Teenagers. British Medical Journal, 323, 480-484. https://doi.org/10.1136/bmj.323.7311.480

[14] Kaukiainen, A., Salmivalli, C., Lagerspetz, K., Tamminen, M., Vauras, M., Maki, H., et al. (2002) Learning Difficulties, Social Intelligence, and Self-Concept: Connections to Bully-Victim Problems. Scandinavian Journal of Psychology, 43, 269-278. https://doi.org/10.1111/1467-9450.00295

[15] Woods, S. and Wolke, D. (2004) Direct and Relational Bullying among Primary School Children and Academic Achievement. Journal of School Psychology, 42, 135-155. https://doi.org/10.1016/j.jsp.2003.12.002

[16] Peterson, J.S. and Ray, K.E. (2006) Bullying and the Gifted: Victims, Perpetrators, Prevalence, and Effects. Gifted Child Quarterly, 50, 148-168. https://doi.org/10.1177/001698620605000206

[17] Carlson, K.T. (2006) Poverty and Youth Violence Exposure: Experiences in Rural Communities. Children and Schools, 28, 87-96. https://doi.org/10.1093/cs/28.2.87

[18] Unnever, J.D. and Cornell, D.G. (2003) The Culture of Bullying in Middle School. Journal of School Violence, 2, 5-27. https://doi.org/10.1300/J202v02n02_02

[19] Curtner-Smith, M.E., Culp, A.M., Culp, R., Scheib, C., Owen, K., Tilley, A., et al. (2006) Mothers' Parenting and Young Economically Disadvantaged Children's Relational and Overt Bullying. Journal of Child and Family Studies, 15, 171-189. https://doi.org/10.1007/s10826-005-9016-7

[20] Hong, J.S. and Espelage, D.L. (2012) A Review of Research on Bullying and Peer Victimization in School: An Ecological System Analysis. Aggression and Violent Behavior, 17, 311-322. https://doi.org/10.1016/j.avb.2012.03.003

[21] Georgiou, S.N. (2009) Personal and Maternal Parameters of Peer Violence at School. Journal of School Violence, 8, 100-119.

https://doi.org/10.1080/15388220802073928

[22] Duncan, R.D. (2004) The Impact of Family Relationships on School Bullies and Victim. In: Espelage, D.L. and Swearer, S.M., Eds., Bullying in American schools: $A$ Social-Ecological Perspective on Prevention and Intervention, Lawrence Erlbaum Associates, Mahwah, 227-244.

[23] Monks, C.P., Smith, P.K., Naylor, P., Barter, C., Ireland, J.L. and Coyne, I. (2009) Bullying in Different Contexts: Commonalities, Differences and the Role of Theory. Aggressive and Violent Behavior, 14, 146-156.

https://doi.org/10.1016/j.avb.2009.01.004

[24] Kennedy, J.H. and Kennedy, C.E. (2004) Attachment Theory: Implication for School Psychology. Psychology in the Schools, 41, 247-259. 
https://doi.org/10.1002/pits.10153

[25] Corvo, K. and de Lara, E. (2010) Towards an Integrated Theory of Relational Violence: Is Bullying a Risk Factor for Domestic Violence? Aggression and Violent Behavior, 15, 181-190. https://doi.org/10.1016/j.avb.2009.12.001

[26] Baldry, A.C. (2003) Bullying in School and Exposure to Domestic Violence. Child Abuse \& Neglect, 27, 713-732. https://doi.org/10.1016/S0145-2134(03)00114-5

[27] Pinarcik, Ö. (2017) Tendency Levels of School Bullying at 24 - 36 Monthly Aged Children. Uluslararası Eğitim Bilimleri Dergisi, No. 12, 40-58.

[28] Feng, J. and Luo, G. (2016) Report on the Injury Accidents of Children at Middle and High Schools in Megacities-Based on the Empirical Investigation in Shanghai. Journal of Youth, No. 3, 74-80.

[29] Espelage, D.L. (2002) Bullying in Early Adolescence: The Role of the Peer Group. Clearinghouse on Elementary and Early Childhood Education, Champaign.

[30] Demaray, M.K. and Malecki, C.K. (2003) Perceptions of the Frequency and Importance of Social Support by Students Classified as Victims, Bullies and Bully/Victims in an Urban Middle School. School Psychology Review, 32, 471-489. https://doi.org/10.1080/02796015.2003.12086213

[31] Wienke Totura, C.M., MacKinnon-Lewis, C., Gesten, E.L., Gadd, R., Divine, K.P., Dunham, S., et al. (2009) Bullying and Victimization among Boys and Girls in Middle School. Journal of Early Adolescence, 29, 571-609. https://doi.org/10.1177/0272431608324190

[32] Kupermine, G.P., Leadbeater, B.J., Emmons, C. and Blatt, S.J.A. (1997) Perceived School Climate and Difficulties in the Social Adjustment of Middle School Students. Developmental Science, 1, 76-88. https://doi.org/10.1207/s1532480xads0102_2

[33] Espelage, D.L. and Swearer, S.M. (2003) Research on School Bullying and Victimization: What Have We Learned and Where Do We Go from Here? School Psychology Review, 32, 365-383. https://doi.org/10.1080/02796015.2003.12086206

[34] Bronfenbrenner, U. (1979) Ecology of Human Development: Experiments by Nature and Design. Harvard University Press, Cambridge.

[35] Lee, C.H. (2009) Personal and Interpersonal Correlates of Bullying Behaviors among Korean Middle School Students. Journal of Interpersonal Violence, 25, 152-176. https://doi.org/10.1177/0886260508329124

[36] Huesmann, L.R., Moise-Titus, J., Podolski, C.L. and Eron, L.D. (2003) Longitudinal Relations between Children's Exposure to TV Violence and Their Aggressive and Violent Behavior in Young Adulthood: 1977-1992. Developmental Psychology, 39, 201-221. https://doi.org/10.1037/0012-1649.39.2.201

[37] Anderson, C.A. and Bushman, B.J. (2001) Effects of Violent Video Games on Aggressive Behavior, Aggressive Cognition, Aggressive Affect, Physiological Arousal, and Prosocial Behavior: A Meta-Analytic Review of the Scientific Literature. Psychological Science, 12, 353-359. https://doi.org/10.1111/1467-9280.00366

[38] Williams, K.R. and Guerra, N.G. (2007) Prevalence and Predictors of Internet Bullying. Journal of Adolescent Health, 41, S14-S21.

https://doi.org/10.1016/j.jadohealth.2007.08.018

[39] Bronfenbrenner, U. (1994) Ecological Models of Human Development. In: Husen, T. and Postlethwaite, T.N., Eds., The International Encyclopedia of Education, 2nd Edition, Elsevier Sciences, New York.

[40] Bond, M.H. (2004) Culture and Aggression: From Context to Coercion. Personality and Social Psychology Review, 8, 62-78. 
https://doi.org/10.1207/s15327957pspr0801_3

[41] Walton, G. (2005) Bullying Widespread: A Critical Analysis of Research and Public Discourse on Bullying. Journal of School Violence, 4, 91-118.

https://doi.org/10.1300/J202v04n01_06

[42] Leach, F. (2003) Learning to Be Violent: The Role of the School in Developing Adolescent Gendered Behavior. Compare, 33, 385-400.

https://doi.org/10.1080/03057920302587 